\title{
Pediatric MDS Including Refractory Cytopenia and Juvenile Myelomonocytic Leukemia
}

\author{
Charlotte M. Niemeyer
}

\subsection{Introduction}

For pediatric patients with MDS and 2-19\% blasts in the PB or $5-19 \%$ blasts in the BM, the same diagnostic criteria utilized for adults with MDS with excess blasts (MDS-EB) are applied (WHO). Some cases with 20-30\% blasts may also have slowly progressive disease, may lack clinical features of acute leukemia, and thus behave more like MDS than AML. These cases of MDS-EB in transformation (MDS-EB- $t$ ) together with cases of MDS-EB account for approximately a quarter of all childhood MDS.

In the large cohort of children with MDS-EB/ MDS-EB-t of the European Working Group of MDS in Childhood (EWOG-MDS), allo-HSCT with a full MAC consisting of the combination of BU/CY/MEL resulted in an OS at 5 years of $63 \%$, with NRM and relapse contributing equally to treatment failure (Strahm et al. 2011). The update shows that the outcome for patients who received a graft from either a MSD or an UD matched for $9 / 10$ or $10 / 10$ HLA-loci by using high-resolution typing is superimposable (Locatelli and Strahm 2018). Because patients $\geq 12$ years of age had a high risk of NRM, EWOG-MDS recommends an intensified GVHD prophylaxis (CSA + MTX) for older patients

C. M. Niemeyer $(\bowtie)$

Department of Pediatrics and Adolescent Medicine,

University Medical Center, Freiburg, Germany

e-mail: charlotte.niemeyer@uniklinik-freiburg.de transplanted from a MSD (see http://ewog-mds. org). The presence of a structurally complex karyotype was found to be strongly associated with poor prognosis (Göhring et al. 2010).

\subsection{Refractory Cytopenia of Childhood (RCC)}

Most children and adolescents with MDS present with RCC, a provisional MDS entity characterized by persistent cytopenia and $<5 \%$ blasts in the $\mathrm{BM}$ and $<2 \%$ blasts in the PB (Baumann et al. 2017). BM biopsy shows considerable hypocellularity in about $80 \%$ of RCC cases. Most of these children with RCC have a normal karyotype and a low risk of progression to MDS-EB, while about $10-15 \%$ display an abnormal karyotype with monosomy $7, \operatorname{del}(7 q)$, or $\geq 2$ aberrations.

It recently became evident that approximately half of all pediatric patients with primary MDS and monosomy 7 or $\operatorname{del}(7 \mathrm{q})$ have GATA2 deficiency or SAMD9/SAMD9L syndrome (Wlodarski et al. 2016). Most of these children present as RCC. Since the presence of monosomy 7 is correlated with a high risk of progression to more advanced MDS, patients with monosomy 7 should generally receive HSCT as soon as possible. For RCC with monosomy 7 , $\operatorname{del}(7 q)$, or $\geq 2$ aberrations, MAC is recommended. EWOG-MDS currently advocates a TREO-based regimen which results in prompt initial engraft- 
ment with a low incidence of secondary graft failure and an OS of approx. 90\% (see http:// ewog-mds.org). Historical data with a BU/CY have provided an OS of approx. 75\%, NRM being the major cause of treatment failure (Starý and Locatelli 2005).

In the absence of monosomy 7, RCC patients with mild cytopenia (no transfusion dependency for red cells or platelets and an absolute neutrophil count of $\geq 1 \times 10^{9} / \mathrm{L}$ ) may have a stable course of disease and therefore qualify for a watch-and-wait strategy. For patients with more pronounced cytopenia, treatment is stratified according to cellularity.

In normo- or hypercellular RCC, a MAC regimen like that described for monosomy 7 may be utilized irrespective of karyotype. In patients with hypocellular BM, Fanconi anemia and dyskeratosis congenita should be excluded by chromosomal breakage and telomere length/ molecular studies, respectively.

HSCT with a RIC is the treatment of choice for hypocellular RCC and normal karyotype (Inagaki et al. 2015; Strahm et al. 2007). HSCT with a preparative regimen of TT/FLU (Strahm et al. 2007) resulted in an OS of $94 \%$ and EFS of $88 \%$ (Strahm et al. 2017). However, approx. 10\% of patients experience primary and secondary graft failure requiring a stem cell boost and/or second HSCT. Thus, EWOG-MDS currently recommends a preparative regimen of TREO/FLU aiming at an improved rate of engraftment (see http://ewog-mds.org). With a very low risk of disease recurrence, GVHD should be avoided; thus, $\mathrm{BM}$ is the preferred stem cell source combined with an effective GVHD prophylaxis (Locatelli and Strahm 2018). In the absence of a suitable donor, IST with horse ATG and CSA may be a therapeutic option in patients with hypocellular RCC and the absence of poor-risk karyotype (Yoshimi et al. 2014).

\subsection{Juvenile Myelomonocytic Leukemia (JMML)}

JMML is a unique clonal hematopoietic disorder of early childhood with myeloproliferative and myelodysplastic features (Locatelli and
Niemeyer 2015). Splenomegaly, leukocytosis, monocytosis, and myeloid and/or erythroid precursors on PB smear are noted in close to all cases. Age $\geq 2$ years, platelet count $<40 \times 10^{9} / \mathrm{L}$, and a high hemoglobin $\mathrm{F}$ are poor prognostic factors.

JMML is characterized by hyperactivation of the RAS signal transduction pathway. About $90 \%$ of patients harbor molecular alteration in 1 of 5 genes (PTPN11, NRAS, KRAS, NF1, CBL) which define genetically and clinically distinct JMML subtypes. PTPN11-, NRAS-, and KRAS-mutated JMMLs are characterized by heterozygous somatic gain-of-function mutations in nonsyndromic children, while JMML in neurofibromatosis type 1 (NF1) and JMML in children with CBL syndrome are characterized by germline RAS disease (RASopathy) and acquired biallelic inactivation of the respective tumor suppressor gene in hematopoietic cells.

JMML with somatic PTPN11 mutations is a rapidly fatal disorder unless the patient undergoes HSCT. HSCT in JMML patients with PTPN11 mutations is followed by a significantly higher relapse rate when compared to patients of the other JMML genetic subtypes. Like PTPN11mutated disease, JMML in patients with NF1 is fatal in the absence of HSCT.

Children with somatic heterozygous KRAS mutations (14\%) often have a clinically particular aggressive form of disease. Close to all of these children require prompt HSCT. NRAS-associated JMML (16\%) displays a great clinical diversity. While a considerable percentage of patients transplanted for JMML with NRAS mutations relapse after HSCT, others survive in the absence of HSCT with persistence of NRAS mutation but slowly regressing disease. Clinically these patients are well and show a normal or only slightly elevated HbF. Molecular studies suggest that children with NRAS mutation and spontaneous regression have a low methylation profile and no subclonal mutations.

The vast majority of children with $C B L$ mutated JMML myeloproliferation is selflimiting with splenomegaly decreasing over years without HSCT. In the absence of one of the five canonical RAS pathway alterations, rare mutations in other RAS genes and non-JMML 
myeloproliferative disorders need to be excluded. Most of these cases require HSCT.

In JMML, allo-HSCT, either from a histocompatible sibling or from an HLA-matched/1antigen-disparate URD, results in a DFS of $52 \%$ (Locatelli et al. 2005). Disease recurrence is the most important cause of failure, occurring with a cumulative incidence of $35 \%$. UCBT is a suitable option for children lacking an HLA-compatible relative (Locatelli et al. 2013). Standard preparative regimen consists of BU/CY/MEL (Locatelli et al. 2005; Dvorak et al. 2018). While intensive chemotherapy prior to transplantation is generally not followed by durable responses, azacitidine might be an attractive option to bridge to HSCT (Cseh et al. 2015).

\section{Key Points}

- Most children and adolescents with MDS present with refractory cytopenia of childhood (RCC). In RCC, bone marrow cells often show a normal karyotype, and there is a low risk of progression to MDS-EB. In the presence of mild cytopenia and a hypocellular marrow, a watch-and-wait strategy may be appropriate; if HSCT is required, a preparative regimen with TREO/FLU results in prompt engraftment.

- In RCC with monosomy 7, del(7q), or $\geq 2$ aberrations and in normo- or hypercellular RCC with any karyotype, MAC HSCT is recommended.

- JMML is characterized by hyperactivation of the RAS signal transduction pathway. About $90 \%$ of patients harbor molecular alteration in 1 of 5 genes (PTPN11, NRAS, KRAS, NF1, CBL) which define genetically and clinically distinct JMML subtypes.

- JMML with somatic PTPN11 mutations is a rapidly fatal disorder in the absence of HSCT. Patients with KRAS mutations often have a clinically particular aggressive disease. NRAS-associated JMML displays a great clinical diversity, some patients have a slowly regressing disease in the absence of HSCT, while others relapse post HSCT. Most $C B L-$ mutated JMML patients have a self-limiting myeloproliferation.

- The standard preparative regimen for HSCT in JMML consists of BU/CY/ MEL.

\section{References}

Baumann I, Niemeyer CM, Bennett JM. Juvenile myelomonocytic leukaemia. In: Swerdlow SH, Campo E, Harris NL, et al., editors. WHO classification of tumors of haematopoietic and lymphoid tissues. Lyon: International Agency for Research on Cancer (IARC); 2017. p. 103-6.

Cseh A, Niemeyer CM, Yoshimi A, et al. Bridging to transplant with azacitidine in juvenile myelomonocytic leukemia: a retrospective analysis of the EWOGMDS study group. Blood. 2015;125:2311-3.

Dvorak CC, Satwani P, Stieglitz E, et al. Disease burden and conditioning regimens in ASCT1221, a randomized phase II trial in children with juvenile myelomonocytic leukemia: A Children's Oncology Group study. Pediatr Blood Cancer. 2018;65:e27034.

Göhring G, Michalova K, Beverloo HB, et al. Complex karyotype newly defined: the strongest prognostic factor in advanced childhood myelodysplastic syndrome. Blood. 2010;116:3766-9.

Inagaki J, Fukano R, Kurauchi K, et al. Hematopoietic stem cell transplantation in children with refractory cytopenia of childhood: single-center experience using high-dose cytarabine containing myeloablative and aplastic anemia oriented reduced-intensity conditioning regimens. Biol Blood Marrow Transplant. 2015;21:565-9.

Locatelli F, Nollke P, Zecca M, et al. Hematopoietic stem cell transplantation (HSCT) in children with juvenile myelomonocytic leukemia (JMML): results of the EWOG-MDS/EBMT trial. Blood. 2005;105:410-9.

Locatelli F, Crotta A, Ruggeri A, et al. Analysis of risk factors influencing outcomes after cord blood transplantation in children with juvenile myelomonocytic leukemia: a EUROCORD, EBMT, EWOG-MDS, CIBMTR study. Blood. 2013;122:2135-41.

Locatelli F, Niemeyer CM. How I treat juvenile myelomonocytic leukemia. Blood. 2015;125:1083-90.

Locatelli F, Strahm B. How I treat myelodysplastic syndromes of childhood. Blood. 2018;131:1406-14.

Starý J, Locatelli F. Niemeyer CM; European Working Group on Myelodysplastic Syndrome (EWOG- 
MDS) and Pediatric Diseases Working Party of the EBMT. Stem cell transplantation for aplastic anemia and myelodysplastic syndrome. Bone Marrow Transplant. 2005;35(Suppl 1):S13-6.

Strahm B, Locatelli F, Bader P, et al. Reduced intensity conditioning in unrelated donor transplantation for refractory cytopenia in childhood. Bone Marrow Transplant. 2007;40:329-33.

Strahm B, Nöllke P, Zecca M, EWOG-MDS study group, et al. Hematopoietic stem cell transplantation for advanced myelodysplastic syndrome in children: results of the EWOG-MDS 98 study. Leukemia. 2011;25:455-62.
Strahm B, Albert M, Bierings M, et al. EWOG-MDS study SCT RC RIC 06: Reduced intensity conditioning for children and adolescents with refractory cytopenia of childhood. Bone Marrow Transplant. 2017;52:S103.

Wlodarski MW, Hirabayashi S, Pastor V, et al. EWOGMDS. Prevalence, clinical characteristics, and prognosis of GATA2-related myelodysplastic syndromes in children and adolescents. Blood. 2016;127:1387-97.

Yoshimi A, van den Heuvel-Eibrink MM, Baumann I, et al. Comparison of horse and rabbit antithymocyte globulin in immunosuppressive therapy for refractory cytopenia of childhood. Haematologica. 2014;99:656-63.

Open Access This chapter is licensed under the terms of the Creative Commons Attribution 4.0 International License (http://creativecommons.org/licenses/by/4.0/), which permits use, sharing, adaptation, distribution and reproduction in any medium or format, as long as you give appropriate credit to the original author(s) and the source, provide a link to the Creative Commons license and indicate if changes were made.

The images or other third party material in this chapter are included in the chapter's Creative Commons license, unless indicated otherwise in a credit line to the material. If material is not included in the chapter's Creative Commons license and your intended use is not permitted by statutory regulation or exceeds the permitted use, you will need to obtain permission directly from the copyright holder. 